\title{
ANALISIS KRITIKALITAS TINGGI TERAS AKTIF HTGR-10MWth DENGAN VARIASI PENGAYAAN PADA KERNEL URANIUM OKSIDA
}

\author{
Hery Adrial \\ Pusat Teknologi dan Keselamatan Nuklir - BATAN \\ Kawasan Puspiptek, Gedung No. 80, Serpong, Tangerang Selatan 15313
}

\begin{abstract}
ABSTRAK
ANALISIS KRITIKALITAS TINGGI TERAS AKTIF HTGR-10MWth DENGAN VARIASI PENGAYAAN PADA KERNEL URANIUM OKSIDA. HTGR-10MWth merupakan salah satu bentuk dari reaktor HTGR tipe pebble bed. Reaktor jenis ini memiliki reaktivitas negatif sebagai fungsi keselamatan melekatnya. Dalam fisika reaktor, parameter kritikalitas merupakan faktor penting untuk mengetahui kondisi kekritisan reaktor, yang menjadi penentu apakah reaktor dapat beroperasi atau tidak. Kritikalitas pada teras aktif suatu reaktor sangat dipengaruhi oleh ketinggian teras aktif, tingkat pengayaan bahan bakar, geometri teras reaktor dan parameter lainnya. Tujuan dari penelitian ini adalah untuk mendapatkan parameter neutronik yang sesuai agar reaktor dapat beroperasi secara optimal. Metodologi yang dilakukan adalah dengan melakukan pemodelan kernel berlapis TRISO dengan model berbentuk kisi-kisi SC (simple cubic), dan pemodelan geometri reaktor. Bahan bakar dan moderator pebble pada teras reaktor dimodelkan dalam bentuk kisi BCC (bodycentered cubic) dengan rasio perbandingan pebble bahan bakar dan pebble moderator sebesar 57:43. Paket program MCNP6 digunakan dalam analisis ini. Dari hasil perhitungan, didapat bahwa tinggi teras aktif kritis awal untuk pengayaan $17 \%$ adalah $125 \mathrm{~cm}$, pengayaan $14 \%$ setinggi $141 \mathrm{~cm}$, pengayaan $12 \%$ adalah $161 \mathrm{~cm}$ dan pengayaan $10 \%$ adalah $196,1 \mathrm{~cm}$. Sementara, tinggi teras aktif penuh untuk pengayaan $8 \%$ melebihi batas tinggi teras yang tersedia.
\end{abstract}

Kata kunci: HTGR 10MWth, kritikalitas, MCNP6, tinggi teras aktif, pengayaan.

\begin{abstract}
ANALYSIS OF CRITICALITY FOR ACTIVE CORE HEIGHT OF HTGR-10 MWTH WITH ENRICHMENT VARIATION OF KERNEL URANIUM OXIDE. HTGR-10 MWth is one type of HTGRs pebble bed reactor. This type of reactors have negative reactivity for their inherent safety functions. In addition, criticality parameters are important factors to find out that a nuclear reactor is in a critical condition so that the reactor can operate. Criticality on the active core of a reactor is strongly influenced by the active core height, the level of fuel enrichment and the reactor core geometry, and othersc. The goal of this research is to obtain the necessary neutron parameters so that the reactor can operate optimally. The methodology used begins with modelling the TRISO-coated kernels with a SC lattice (simple Cubic lattice), followed by reactor geometry modeling. The fuel and pebble moderators on the reactor core were modeled in the lattice of Body Centered Cubic (BCC) with the ratio of fuel pebble and moderator of 57:43. The program package used in the calculation is the MCNP6 code. From the calculation results, it is obtained that the initial active core height for enrichment of $17 \%$ is $125 \mathrm{~cm}$, for enrichment $14 \%$ as high as $141 \mathrm{~cm}$, for enrichment 12 $\%$ is $161 \mathrm{~cm}$ and for enrichment $10 \%$ is $196.1 \mathrm{~cm}$, while for enrichment $8 \%$ the core height is beyond the available limit.
\end{abstract}

Keywords: HTGR $10 \mathrm{MWth}$, criticality, MCNP6, active core height, enrichment 


\section{PENDAHULUAN}

HTGR pebble bed merupakan reaktor Generasi IV berpendingin gas yang paling menjanjikan dan populer perkembangannya dalam dekade terakhir ini. Hal tersebut karena HTGR pebble bed memiliki sistem keselamatan melekat, reaktivitas temperatur negatif, efisiensi termal lebih baik serta temperatur keluaran yang tinggi. Aspek terakhir membuat HTGR dapat dimanfaatkan dalam berbagai aplikasi industri, seperti pembangkitan hidrogen, desalinasi, enhanced oil recovery serta aplikasi industri lainnya yang membutuhkan panas tinggi [1]. Dengan demikian, energi keluaran yang dibangkitkan HTGR pebble bed dapat berfungsi sebagai sumber energi panas untuk proses industri.

HTGR pertama kali dikembangkan pada tahun 1944 di Oak Ridge, Amerika Serikat. Selanjutnya, beberapa negara turut mengembangkan proyek HTGR, diantaranya Inggris dalam rentang tahun 1964-1974 dengan proyek Dragon, Jerman antara tahun 1967-1988 dengan proyek AVR (Arbeitsgemeinschaft Versuchs Reaktor) serta proyek THTR (Thorium High Temperature Reactor) pada tahun 1986-1989. Sementara, Amerika Serikat sendiri turut berperan dengan proyek Peach Bottom (1967-1974) dan proyek demonstrasi teknologi HTGR di Fort St.
Vrain dalam kurun tahun 1976-1989 [2-4].

Dewasa ini, ada beberapa proyek HTGR yang sedang dalam taraf perencanaan maupun konstruksi, yaitu PBMR Afrika Selatan, HTR-PM Cina, GTHTR300C Jepang, GT-MHR Rusia, ANTARES Perancis, NHDD Korea Selatan dan NGNP Amerika Serikat [5-8].

HTGR dapat dibagi menjadi 2 jenis, yakni tipe prismatik dan tipe pebble bed. Tipe prismatik banyak dikembangkan di Amerika Serikat dan Jepang, sedangkan pebble bed dikembangkan di Jerman, Rusia, Swiss, Afrika Selatan dan Cina. HTGR prismatik yang masih beroperasi adalah HTTR (high temperature engineering test reactor) yang digunakan sebagai fasilitas uji di Jepang, sedangkan untuk tipe pebble bed adalah HTR-10 yang difungsikan sebagai reaktor eksperimen di Cina.

HTGR-10MWth merupakan desain HTGR pebble bed yang mengacu pada HTR-10. Reaktor ini didesain menggunakan bahan bakar dan moderator berbentuk pebble (bola). Untuk mendukung sistem keselamatan pasif dan melekat, konstruksi HTGR-10MWth sangat didominasi oleh grafit. Pada HTGR, grafit digunakan sebagai material sruktur, reflektor neutron dan moderator karena grafit mempunyai sifat mekanik yang baik dalam kondisi radiasi yang tinggi $[9,10]$. 
Dalam fisika reaktor nuklir, faktor multiplikasi merupakan parameter penting untuk mengetahui kondisi kekritisan suatu reaktor. Nilai faktor multiplikasi sangat dipengaruhi oleh berbagai faktor, diantaranya ketinggian teras aktif, tingkat pengayaan bahan bakar maupun geometri teras. Oleh karena itu, dalam penelitian ini dilakukan analisis kritikalitas tinggi aktif teras HTGR-10MWth dengan variasi pengayaan pada kernel uranium oksida. Asumsi yang digunakan adalah sebagai berikut.

1. Daya 10MWth;

2. Tinggi teras yang dianalisis mulai dari $80 \mathrm{~cm}$ hingga $197 \mathrm{~cm}$;

3. Kernel bahan bakar terbuat dari $\mathrm{UO}_{2}$ dengan densitas $10,4 \mathrm{~g} / \mathrm{cc}$;

4. Rasio bahan bakar terhadap moderator (f:m) sebesar 57:43;

5. Perubahan temperatur operasi dilakukan pada $300{ }^{\circ} \mathrm{C}, 600{ }^{\circ} \mathrm{C}, 900$ ${ }^{\circ} \mathrm{C}$ dan $1200{ }^{\circ} \mathrm{C}$.

Paket program yang digunakan untuk simulasi adalah MCNP6. Hasil analisis digunakan untuk mendapatkan parameter neutronik yang diperlukan agar reaktor dapat beroperasi secara optimal. MCNP6 merupakan versi terbaru dari MCNP, yang merupakan perangkat lunak yang dapat mensimulasikan interaksi partikel dalam reaktor nuklir dengan metode Monte Carlo. MCNP6 memanfaatkan pustaka data tampang lintang nuklir energi kontinu ENDF/B-VII. Pada penelitian ini, bahan bakar dan moderator pebble dalam teras reaktor dimodelkan dalam kisi BCC (bodycentered cubic), sementara kernel $\mathrm{UO}_{2}$ berlapis TRISO (TRistructural-ISOtropic) yang tersebar di dalam pebble dimodelkan dalam bentuk kisi SC (simple cubic) [11$15]$.

\section{DESKRIPSI HTGR-10MWth PEBBLE BED}

HTGR-10MWth pebble bed merupakan reaktor nuklir temperatur tinggi berpendingin gas. HTGR-10MWth pebble bed didesain memiliki temperatur masuk sebesar $250{ }^{\circ} \mathrm{C}$ dan temperatur keluar sebesar $750{ }^{\circ} \mathrm{C}$ dengan tekanan operasional $3 \mathrm{MPa}$. Media pendingin yang digunakan adalah helium yang bersifat tidak korosif dan transparan terhadap neutron. HTGR10MWth mempunyai teras aktif setinggi $197 \mathrm{~cm}$ dengan radius sebesar $90 \mathrm{~cm}$. Pada bagian bawah teras terdapat corong setinggi $36 \mathrm{~cm}$, dengan radius atas sebesar $90 \mathrm{~cm}$ dan radius bawah sebesar $25 \mathrm{~cm}$. Pada awal pengoperasian, corong tersebut diisi oleh pebble moderator. Teras dikelilingi grafit reflektor, bejana bertekanan stainless steel dengan ketebalan $8 \mathrm{~cm}$, RCCS (reactor cavity cooling system) serta pengungkung beton. Pada bagian blok reflektor terdapat 10 lubang saluran batang kendali dengan diameter 
masing-masing $6,5 \mathrm{~cm}, 7$ lubang saluran bola absorber kecil berbentuk kapsul, 3 lubang saluran iradiasi berdiameter $6,5 \mathrm{~cm}$ serta 20 lubang saluran pendingin berdiameter $4 \mathrm{~cm}$ [16-19]. Dari sisi aksial, di atas teras aktif terdapat ruang hampa setebal $41 \mathrm{~cm}$ dan reflektor atas setebal 16 $\mathrm{cm}$. Sementara, bagian bawah teras aktif diselubungi dengan blok grafit. Bersebelahan dengan sistem teras reaktor terdapat sistem perpindahan panas. Visualisasi teras HTGR-10MWth pebble bed dapat dilihat pada Gambar 1.

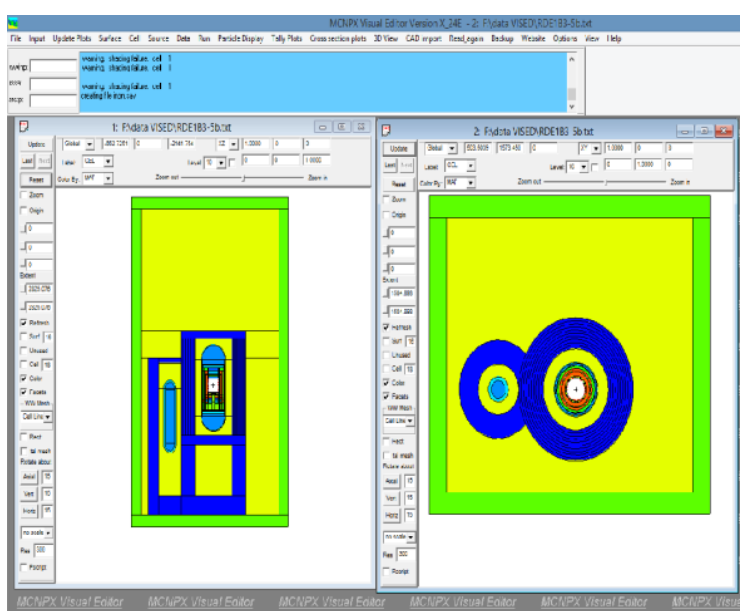

Gambar 1. Visualisasi HTGR10MWth mengunakan paket program VISED

Bahan bakar HTGR-10MWth pebble bed berbentuk pebble (bola) grafit berdiameter $6 \mathrm{~cm}$ yang di dalamnya terdapat zona bahan bakar berisi 8335 kernel $\mathrm{UO}_{2}$ berlapis partikel TRISO [20]. Densitas kernel $\mathrm{UO}_{2}$ yang digunakan sebesar $10,4 \mathrm{~g} / \mathrm{cm}^{3}$ dengan radius 0,025 $\mathrm{cm}$.
TRISO merupakan lapisan pembungkus kernel $\mathrm{UO}_{2}$ yang terdiri dari 4 lapisan [20-23], yaitu lapisan penyangga karbon berpori (porous carbon buffer) dengan ketebalan 0,009 cm, berfungsi untuk menampung gas-gas hasil produk fisi yang berasal dari kernel serta mengantisipasi terjadinya swelling pada kernel bahan bakar. Lapisan kedua merupakan lapisan piro karbon bagian dalam (inner pyrolitic carbon, IPyC) dengan ketebalan $0,004 \mathrm{~cm}$, berguna sebagai lapisan penahan difusi produk fisi dan untuk mencegah berinteraksinya $\mathrm{CO}$ dengan $\mathrm{SiC}$.

Lapisan ketiga adalah lapisan silikon karbida ( $\mathrm{SiC}$ ) dengan ketebalan $0,0035 \mathrm{~cm}$, berfungsi menjadi penahan primer terhadap produk fisi baik berupa gas maupun padatan pada temperatur dibawah $1250{ }^{\circ} \mathrm{C}$. Lapisan terakhir adalah lapisan piro karbon bagian luar (outer pyrolitic carbon, OPyC) dengan ketebalan 0,004 $\mathrm{cm}$. Lapisan ini menjadi lapisan terakhir yang menahan keluarnya produk fisi dengan fasa gas dan merupakan lapisan yang berikatan dengan elemen matriks bahan bakar [24]. Kernel-kernel berlapis TRISO tersebut terdispersi dalam matrik grafit yang berada pada zona bahan bakar. Visualisasi pebble bahan bakar dan moderator dapat dilihat pada Gambar 2. 

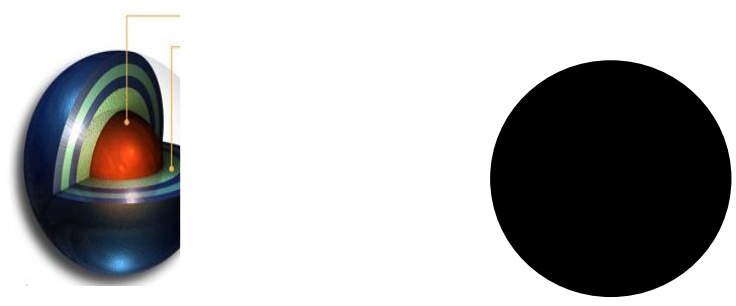

Gambar 2. Visualisasi pebble bahan bakar dan moderator [25]

\section{METODOLOGI}

Penelitian ini diawali dengan melakukan pemodelan kernel berlapis TRISO. Selanjutnya, dilakukan pemodelan kisi partikel bahan bakar TRISO yang berada pada zona bahan bakar pebble. Model kisi berbentuk SC dengan pitch sebesar 0,198762 $\mathrm{cm}$ dan fraksi packing TRISO sebesar 5,024811\%. Kemudian, dilakukan pemodelan pebble bahan bakar yang terdiri dari daerah cangkang grafit dengan ketebalan 0,5 $\mathrm{cm}$ dan densitas 1,75 $\mathrm{g} / \mathrm{cm}^{3}$, serta zona bahan bakar berdiameter $5 \mathrm{~cm}$ dan berisi 8335 butir partikel TRISO.

Visualisasi bentuk bahan bakar pebble dapat dilhat pada Gambar 3.

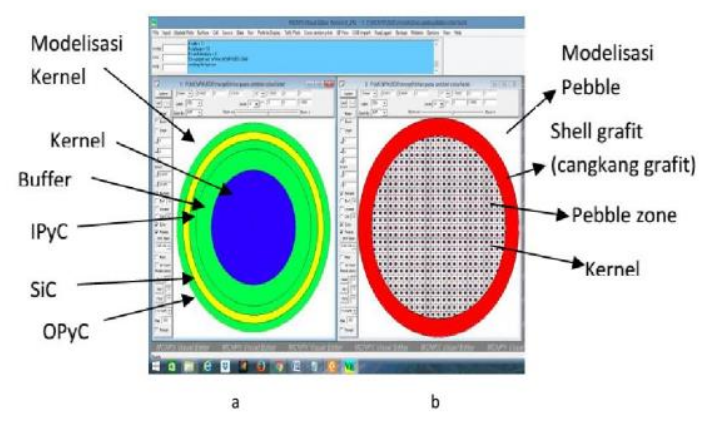

Gambar 3. Visualisasi modelisasi pebble bahan bakar HTGR 10MWth dengan MCNP6
Langkah berikutnya, dilakukan pemodelan pebble bahan bakar dan moderator di dalam teras dengan packing factor 57 : 43. Model dibuat dalam bentuk kisi BCC. Pada model ini, satu pebble bahan bakar ditempatkan pada pusat kisi sedangkan 1/8 pebble moderator berada pada pojok-pojok kisi.

Dengan demikian, dalam satu kisi terdapat 2 pebble yang terdiri dari 1 pebble bahan bakar dan 1 pebble moderator. Rasio bahan bakar terhadap moderator (F/M) akan mempengaruhi radius masing-masing pebble dan panjang pitch pada model kisi BCC. Untuk rasio $\mathrm{F} / \mathrm{M}=57: 43$ panjang pitch yang digunakan adalah $6.877 \mathrm{~cm}$ dan fraksi packing pebble sebesar $61 \%$. Pada kisi-kisi juga dimodelkan pendingin helium yang mengisi ruang antara pebble bahan bakar dan pebble moderator. Visualisasi model pebble bahan bakar, moderator dan pendingin helium disajikan pada Gambar 4.

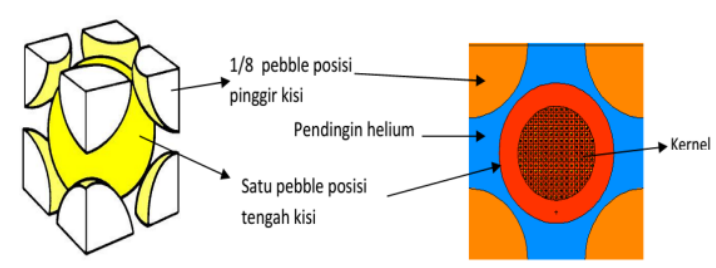

Gambar 4. Visualisasi dan pemodelan kisi BCC [26]

Terakhir, dilakukan perhitungan kritikalitas dalam berbagai ketinggian teras dan variasi pengayaan, yang dilanjutkan dengan perhitungan perubahan reaktivitas 
terhadap perubahan temperatur operasi reaktor.

\section{HASIL DAN PEMBAHASAN}

Berdasarkan perhitungan kritikalitas pada berbagai ketinggian teras dan tingkat pengayaan menggunakan MCNP6, didapatkan hasil sebagaimana ditampilkan pada Gambar 5.

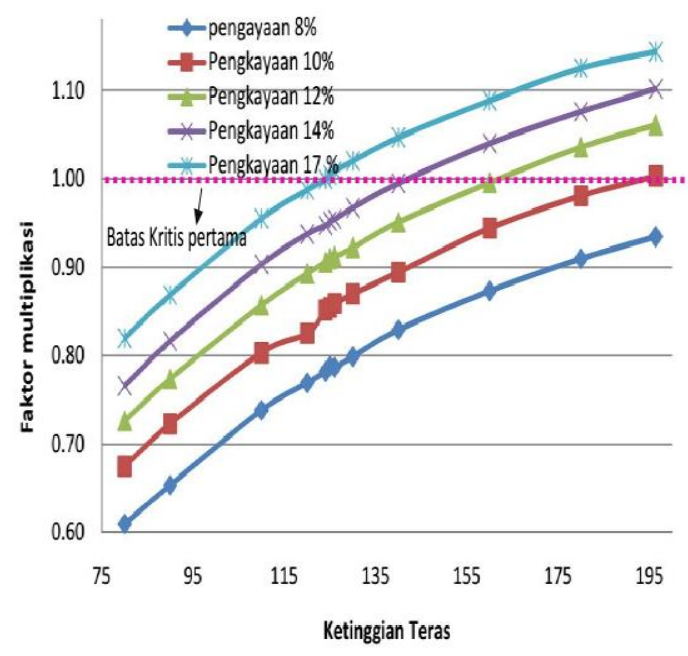

Gambar 5. Nilai kritikalitas terhadap ketinggian teras untuk beberapa tingkat pengayaan.

Berdasarkan Gambar 5, terlihat bahwa ketinggian teras kritis pada kondisi awal semakin bertambah seiring dengan berkurangnya tingkat pengayaan bahan bakar. Dengan tingkat pengayaan bahan bakar 17\%, tinggi teras kritis pertama dicapai pada tinggi $125 \mathrm{~cm}$. Dalam penelitian-penelitian lain pada reaktor HTR-10 Cina dengan pengayaan bahan bakar serupa didapatkan hasil ketinggian teras kritis pertama yang relatif mendekati, yaitu 123,06 cm [27], 123,57 cm dengan menggunakan paket VSOP oleh Jing et al. [28] dan 130,15 cm dengan MCNP pada penelitian di KAIST [29].

Hasil perhitungan untuk hubungan pengayaan bahan bakar terhadap tinggi teras kritis pertama secara lengkap dapat dilihat pada Tabel 1 dan diperjelas pada Gambar 6.

Tabel 1. Hubungan pengayaan bahan bakar terhadap tinggi teras kritis pertama

\begin{tabular}{|r|r|r|}
\hline \multicolumn{1}{|r|}{ No } & $\begin{array}{c}\text { Pengkayaan } \\
\text { UO2 (\%) }\end{array}$ & $\begin{array}{c}\text { Tinggi Teras } \\
\text { kritis pertama } \\
(\mathrm{cm})\end{array}$ \\
\hline 1 & 17.00 & 125 \\
\hline 2 & 14.00 & 141 \\
\hline 3 & 12.00 & 161 \\
\hline 4 & 10.00 & 196.1 \\
\hline 5 & 8.00 & $\begin{array}{c}\text { Diluar teras } \\
\text { tersedia }\end{array}$ \\
\hline
\end{tabular}

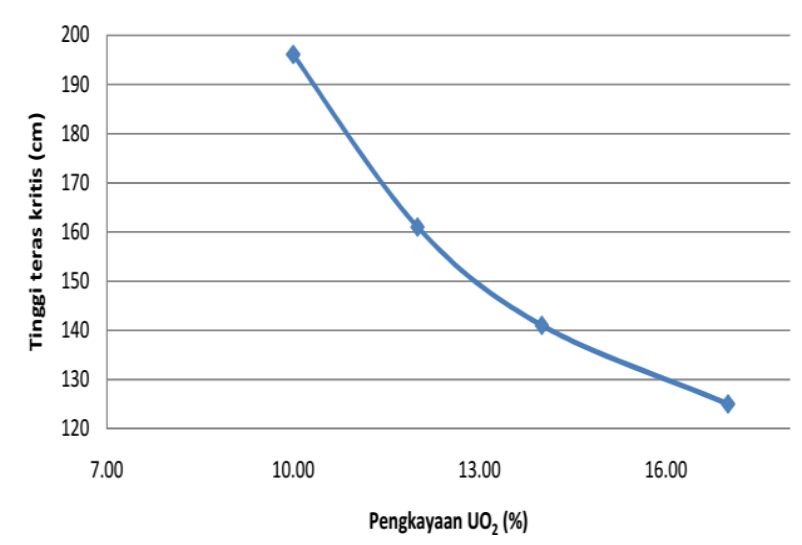

Gambar 6. Kurva hubungan pengayaan bahan bakar terhadap tinggi teras pertama Mengacu pada Tabel 1 maupun Gambar 6, terlihat bahwa semakin rendah tingkat pengayaan bahan bakar, maka dibutuhkan teras yang lebih tinggi untuk mencapai teras kritis pertama. Pada pengayaan bahan bakar $8 \%$ ketinggian 
teras yang dibutuhkan melampaui batasan teras reaktor, yakni $197 \mathrm{~cm}$. Kondisi ini terjadi karena, semakin tinggi tingkat pengayaan bahan bakar, semakin banyak pula bahan fisil di dalam teras. Efeknya, reaksi fisi yang terjadi pada teras reaktor akan semakin banyak. Dengan demikian, pada kondisi pengayaan tinggi, hanya dibutuhkan ketinggian teras rendah untuk mendapatkan teras kritis pertama.

Pada penelitian ini juga dilakukan perhitungan perubahan reaktivitas terhadap perubahan temperatur teras untuk teras dengan ketinggian paling rendah dan teras penuh pertama. Hasil perhitungan tersebut dapat dilihat pada Gambar 7 dan Gambar 8.

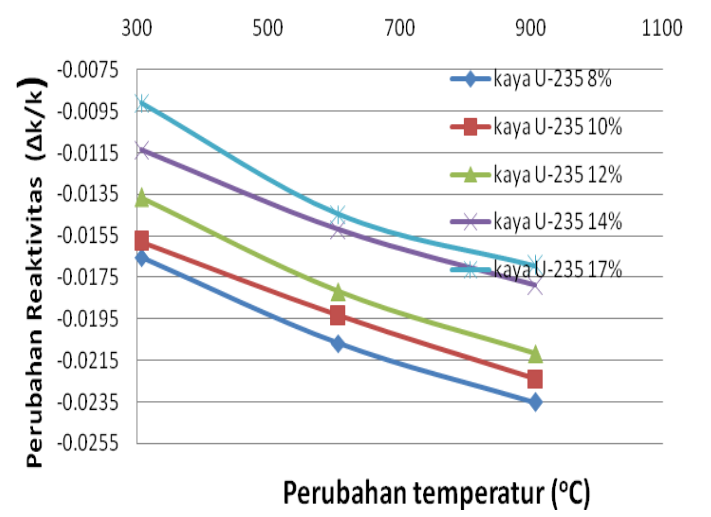

Gambar 7. Hubungan perubahan reaktivitas terhadap perubahan temperatur pada ketinggian teras aktif $80 \mathrm{~cm}$

Dari Gambar 7 terlihat bahwa semakin rendah pengayaan maka semakin kecil pula nilai reaktivitas negatifnya. Seiring dengan bertambahnya perbedaan temperatur, nilai reaktivitas negatif pun semakin besar. Hal ini menunjukkan bahwa kenaikan temperatur reaktor berbanding lurus terhadap peningkatan absorbsi neutron dalam teras. Dengan demikian, reaktor semakin tanggap untuk menuju subkitis.

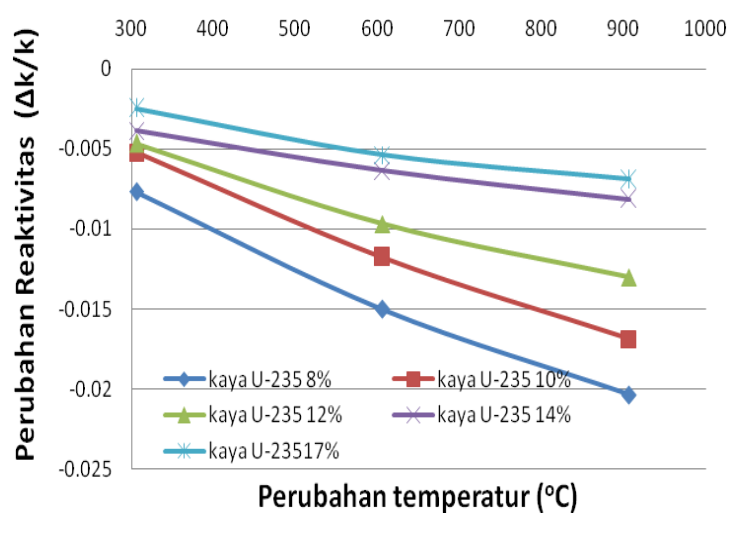

Gambar 8. Hubungan perubahan reaktivitas terhadap perubahan temperatur pada ketinggian teras aktif $197 \mathrm{~cm}$

Gambar 8 menunjukkan perubahan reaktivitas untuk kondisi teras penuh pertama. Terlihat bahwa beda temperatur $300{ }^{\circ} \mathrm{C}$ menghasilkan nilai reaktivitas negatif sangat kecil. Artinya, pada perbedaan temperatur $300{ }^{\circ} \mathrm{C}$, tanggapan reaktor untuk menuju subkritis sangat kecil. Dengan kata lain, sulit untuk membuat reaktor subkritis.

\section{KESIMPULAN}

Pada HTGR-10MWth dengan tinggi teras maksimal $197 \mathrm{~cm}$, teras kritis pertama efektif dapat dicapai pada tingkat pengayaan $\mathrm{UO}_{2}$ dari $10 \%$ hingga $17 \%$. Pengayaan dibawah $10 \%$ tidak mampu mencapai teras kritis pada batasan yang 
tersedia. Pada tingkat pengayaan 17\%, tinggi teras kritis pertama adalah setinggi $125 \mathrm{~cm}$. Semakin tinggi pengayaan kernel $\mathrm{UO}_{2}$ semakin rendah ketinggian teras kritis pertama yang dicapai. Pada kondisi teras penuh, semakin tinggi beda temperatur maka semakin besar nilai perubahan reaktivitas negatif, yang berarti semakin mudah untuk membuat teras menjadi subkritis. Sedangkan untuk ketinggian teras aktif yang paling rendah (tinggi teras aktif $80 \mathrm{~cm}$ ), maka nilai perubahan reaktivitas negatif lebih tinggi dibandingkan kondisi teras penuh. Untuk semua kondisi ketinggian teras, HTGR 10MWth selalu mempunyai reaktivitas negatif.

\section{UCAPAN TERIMAKASIH}

Penulis mengucapkan terima kasih kepada Dr. Syaiful Bakhri sebagai Manajer Program INSINAS-Flagship dan Dr.Geni Rina Sunaryo, M.Sc. sebagai Kepala Program INSINAS-Unggulan dan Kepala Pusat Teknologi dan Keselamatan Reaktor Nuklir (PTKRN) - BATAN atas saran dan perbaikannya. Demikian pula kepada Ir. Zuhair, M.Eng, yang telah menyediakan waktu untuk berdiskusi tentang materi penulisan ini. Makalah ini didanai oleh Kementerian Riset, Teknologi, dan Pendidikan Tinggi Republik Indonesia melalui INSINAS-Flagship Grant Program TA 2018.

\section{DAFTAR PUSTAKA}

1. J. ROSALES, et al., "Computational Model for the Neutronic Simulation of Pebble Bed Reactor's Core Using MCNPX", International Journal of Nuclear Energy, Volume 2014, Article ID 279073, DOI: http://dx.doi.org/10.1155/2014/27907 3 (2014).

2. ANONYMOUS, "Plutonium in High Temperature Reactors", DRAGON Project Report 899, 1974.

3. ANONYMOUS, "AVR Experimental High-Temperature Reactor, 21 Years of Successful Operation for a Future Energy Technology”, Association of German Engineers (VDI) - The Society for Energy Technologies (Publ.), Duesseldorf, June 1990.

4. ANONYMOUS, "HTR-GmbH: THTR-300 MW Kernkraftwerk Hamm-Uentrop", Kurzbeschreibung, December 1983.

5. ANONYMOUS, "Reactor Safety Analysis Report of the South-African Pebble bed Modular Reactor (PBMR)", Rev. E, PBMR Ltd., Centurion, South-Africa, 2000.

6. KAZUHIKO KUNITOMI, XING YAN, SHUSAKU SHIOZAWA, NOZIOMU FUJIMOTO, "GTHTR 300C for Hydrogen Cogeneration", The 2-nd International Topical 
Meeting on High Temperature

Reactor Technology (HTR-2004),

Beijing, Cina, September 22-24, 2004.

7. JEAN-CLAUDE HAUTHIER, GERD BRINKMANN, BERNIE COPSEY, MICHEL LECOMTE, "ANTARES: The HTR/VHTR Project at Framatome ANP", The 2nd International Topical Meeting on High Temperature Reactor Technology (HTR-2004), Beijing, Cina, September 22-24, 2004.

8. ANONYMOUS, "Next Generation Nuclear Plant - Design Methods Development and Validation Research and Development Program Plan”, Idaho National Engineering and Environmental Laboratory, INEEL/EXT-04-02293 Rev. 0, September 2004.

9. ZHEN $\mathrm{Hu}$, et al, "CO2 corrosion of IG-110 nuclear graphite studied by gas chromatography", Journal of Nuclear Science and Technology 51 (487-492) 4,2014. DOI: http://dx.doi.org/10.1080/00223131.2 $\underline{013.877407 .}$.

10. XUEGANG LIU, et al, "Source Term Analysis of the Irradiated Graphite in the Core of HTR-10", Science and Technology of Nuclear Installations Volume 2017, Article ID 2614890, 6 pages DOI: https://doi.org/10.1155/2017/261489

$\underline{0}$.

11. SUWOTO, ZUHAIR, “Analisis Laju Dosis Neutron Teras RGTT200K dengan MCNP", Jurnal Sains dan Teknologi Nuklir Indonesia 17(107121) 2, 2016

DOI: http://dx.doi.org/10.17146/jstni.2016. 17.2.2350.

12. ZUHAIR, SUWOTO, T. SETIADIPURA, Z. SU'UD, “The Effects of Applying Silicon Carbide Coating on Core Reactivity of Pebble bed HTR in Water Ingress Accident", Kerntechnik 82(92-97) 1, 2017 DOI: https://doi.org/10.3139/124.110628.

13. SUWOTO, ZUHAIR, "Analisis Sensitivitas Ketebalan Reflektor Grafit Teras RGTT200K menggunakan Perhitungan Monte Carlo", Jurnal Pengembangan Energi Nuklir 16 (73-83) 2, 2014.

14. ZUHAIR, SUWOTO, P. SUPRIATNA, "Studi Efek Fraksi Packing Triso dalam Desain Kritikalitas RGTT200K", Seminar Nasional ke-17 Teknologi dan Keselamatan PLTN serta Fasilitas Nuklir, Yogyakarta, 2011.

15. ZUHAIR, SUWOTO, “Analisis Efek Kecelakaan Water Ingress terhadap Reaktivitas Doppler Teras RGTT200K“, Jurnal Teknologi 
Reaktor Nuklir TRI DASA MEGA, 17(31-40) 1, 2015.

16. HERY ADRIAL, ZUHAIR, SUWOTO, SYAIFUL BAKHRI, GENI RINA SUNARYO, "Effect of F/M Ratio Against Neutron Flux Distribution on the HTGR-10MWth Pebble Bed Core", Prosiding Seminar Nasional Teknologi Energi Nuklir, Makassar, 12 Oktober 2017.

17. SUWOTO, H. ADRIAL, A. HAMZAH, ZUHAIR, S. BAKHRI, G.R. SUNARYO, "Neutron Dose Rate Analysis on HTGR-10 Reactor using Monte Carlo Code, Journal of Physics: Conference Series 962 (1), 012029, 2018.

18. ZUHAIR, SUWOTO, PIPING SUPRIATNA, "Studi Model Heksagonal MCNP5 dalam Perhitungan Benchmark Fisika Teras HTR-10”, Jurnal Matematika \& Sains, 17(61-70) 2, 2012.

19. ZUHAIR, P.I. YAZID, J.S. PANE, "Studi Model Benchmark MCNP6 Dalam Perhitungan Reaktivitas Batang Kendali HTR-10", GANENDRA Majalah IPTEK Nuklir 19(95-103) 2, 2016 DOI: http://dx.doi.org/10.17146/gnd.2016. 19.2.2880.

20. HERY ADRIAL, SUWOTO, ZUHAIR, "Analysis on Fuel Inventory of HTGR10MWth Pebble
Bed Base on Burnup Levels Variation using MCNPX", Prosiding Seminar Nasional Teknologi Energi Nuklir, Batam 4-6 Agustus 2016.

21. SUWOTO, HERY ADRIAL, ZUHAIR, "Analisis Kuat Sumber Neutron Dan Perhitungan Laju Dosis Neutron Teras pertama RDE”, Urania Jurnal Ilmiah Daur Bahan Bakar Nuklir 23(33-44) 1, 2017 DOI: https://doi.org/10.17146/urania.2017. 23.1.3119.

22. ZUHAIR, SUWOTO, PUTRANTO ILHAM YAZID， "Investigasi Parameter Bahan Bakar Pebble dalam Perhitungan Teras Thorium RGTT200K”, Jurnal Sains dan Teknologi Nuklir Indonesia, 14(6578) 2, 2013.

23. ZUHAIR, SUWOTO, T. SETIADIPURA, S. BAKHRI, G. R. SUNARYO, "Study on Characteristic of Temperature Coefficient of Reactivity for Plutonium Core of Pebbled Bed Reactor", Journal of Physics: Conference Series 962 (1), 012058, 2018 .

24. S. A. HOSSEINI, "Neutronic Analysis of a Gaseous Control System for the HTR-10 Reactor", Annals of Nuclear Energy, 45 (8085), 2012. 
25. https://inis.iaea.org/collection/NCLC ollectionStore/_Public/37/122/37122 251.pdf.

26. HERY ADRIAL, "Efek Impuritas Boron pada Kernel Bahan Bakar HTGR Pebble Bed", SIGMA EPSILON-Buletin Ilmiah Teknologi Keselamatan Reaktor Nuklir, 21(1), 2017.

27. WILLIAM K. TERRY, et al., "Evaluation of the HTR-10 Reactor as a Benchmark for Physics Code QA”, PHYSOR-2006, ANS Topical Meeting on Reactor Physics, September 2006.

28. HYEDONG JEONG, SOON HEUNG CHANG, "Estimation of the Fission Products, Actinides and Tritium of HTR-10", Nuclear Engineering and Technology, 41 (5), 2009.

29. HONG-CHUL KIM, SONG HYUN KIM, JONG KYUNG KIM, “A New Strategy to Simulate a Random Geometry in a Pebble bed Core with the Monte Carlo Code MCNP", Annals of Nuclear Energy 38 (18771883), 2011. 